\title{
Molecular Intactness of Transferrin Recycled in a Myogenic Chicken Cell Culture
}

\author{
Ichiro Kimura, Takayuki Hasegawa ${ }^{1}$ and Eijiro Ozawa \\ Division of Cell Biology, National Center for Nervous, Mental and Muscular \\ Disorders, 4-1-1 Ogawa-Higashi-Machi, Kodaira, Tokyo 187, Japan
}

\begin{abstract}
Evidence has been accumulating that transferrin (Tf), an ironbinding glycoprotein, is a unique ligand in that it is recycled intact. We examined the properties of chicken $\mathrm{Tf}$ molecules recycled in a myogenic chicken cell culture. No difference in the isoelectric focusing pattern before and after recycling, nor any marked change in the total $\mathrm{Tf}$ concentration in the culture medium was found during culture. And, although recycled Tf had no myotrophic activity in vitro, it regained its original activity when reloaded with iron. These results are evidence of the molecular intactness of recycled Tf.
\end{abstract}

Transferrin (Tf), an iron-binding glycoprotein (19), is an indispensable iron-donor for the in vitro growth of almost all types of mammalian cells $(2,3)$. Iron-loaded Tf is taken up by a Tf receptor and internalized via the coated pit and receptosome (or endosome). The path of the Tf ligand is of particular interest because, after delivering its iron to a cell within an acidic nonlysosomal organelle, it returns intact to the extracellular medium instead of being directed to the lysosome as are other ligands $(4,5,8,12,18,24)$. The molecular intactness of recycled $\mathrm{Tf}$ has not yet been satisfactorily demonstrated. Intactness has been suggested by the retention of its acid precipitability and molecular weight as determined on sodium dodecyl-sulfatepolyacrylamide gel $(12,19)$; but the possibility cannot be ruled out that minor alterations in the molecular structure of Tf might occur. The study reported here was done to confirm the molecular intactness of chicken $\mathrm{Tf}$ recycled in myogenic chicken cell culture.

Polyacrylamide-gel isoelectric focusing (PAGIF) with direct immunofixation (DIF) was used both to examine the molecular intactness of and to ascertain the loss of iron from holoTf. The concentration of chicken Tf in the culture medium was determined by PAGIF, DIF, staining and densitometry. Intactness also was examined by testing whether recycled Tf molecules could regain their in vitro myotrophic activity when reloaded with iron. Here, we report further evidence for the molecular intactness of $\mathrm{Tf}$ during recycling.

\footnotetext{
1 Present address: Laboratory of Molecular Biology, National Institute of Health, Bethesda, MD 20205, U.S.A.

Abbreviations used: Tf, transferrin; oTf, ovotransferrin; PAGIF, polyacrylamide-gel isoelectric focusing; DIF, direct immnofixation; CK, creatine kinase; IgG, gamma globulin; CB, citratebicarbonate solution; FeCB, CB containing iron; FCM, fresh culture medium; UCM, used culture medium.
} 


\section{MATERIALS AND METHODS}

Cells and cell cultures. Myogenic chicken cells were prepared from the breast muscle of 11-day-old embryos by scissoring and mild pipette agitation (15). The culture medium used was composed of Eagle's minimum essential medium (MEM, Nissui Co. Ltd., Japan) and horse serum (Gibco Lab., U.S.A., Control No. 23K4122) with or without the additions specified in the text. The cells were cultured in gelatin-coated $35-\mathrm{mm}$ Falcon dishes, the cultures being maintained at $37^{\circ} \mathrm{C}$ under a humidified atmosphere of $5 \% \mathrm{CO}_{2}$ and $95 \%$ air. Details of the other culture conditions are described in the text and in the table and figure legends.

Assay of creatine kinase. As an index of myogenic cell growth, the creatine kinase (CK) activity in the myotubes was assayed. After incubation for varying periods, the culture medium was decanted and the cells washed twice with $0.15 \mathrm{M} \mathrm{NaCl}-1 \mathrm{mM} \mathrm{CaCl}$. Then, $1.2 \mathrm{ml}$ of ice-cold $1 \%$ Triton X-100 was poured into the dish, and the cells were detached and made soluble with a rubber policeman. The cell lysate was stored at $-20^{\circ} \mathrm{C}$ prior to assay.

For the assay of CK activity the cell lysate was thawed and spun for $5 \mathrm{~min}$ in an Eppendorf centrifuge (type 5412, Brinkman Instruments, U.S.A.). The supernatant formed was used as the enzyme solution. CK was assayed using a diagnostic kit (CK-NAK, Boehringer Mannheim GmbH, W. Germany) and a kinetic analyzer (Ultrolab System 2086 Mark II, LKB Pordukter AB, Sweden) according to the procedures recommended by the manufacturers.

Transferrins. Chicken serum Tfs (Tf 1 and $\mathrm{Tf} 2$ ) was purified from adult serum and ovoTf (oTf) from egg white, as described elsewhere (15). Tf 1 and Tf 2 are subspecies which respectively bear one and two terminal sialic acid residues in their carbohydrate chains; oTf bears no sialic acid residue. When Tf 1 and Tf 2 were completely desialylated by neuraminidase, their asialo-derivatives were indistinguishable from oTf on PAGIF gel (15). These chicken $T f$ subspecies are indistinguishable in their growth-supporting activities with myogenic chicken cells and in their immunoreactivities to anti-chicken $\mathrm{Tf}$ antibodies (11, $14,17)$.

Iron-loading of $T f s$. In some experiments, the recycled Tf (apoTf) in culture medium was reloaded with iron as follows (15): For PAGIF analysis, "used" culture medium was mixed with $1 / 100$ volume of $0.1 \mathrm{M}$ sodium citrate- $0.1 \mathrm{M}$ sodium bicarbonate, $\mathrm{pH} 8.6$ (CB solution) or $\mathrm{CB}$ solution containing $10 \mathrm{mM} \mathrm{FeCl}_{3}$ ( $\mathrm{FeCB}$ solution). To examine the restoration of its myotrophic activity, we mixed the "used" culture medium with $1 / 1000$ volume of $\mathrm{CB}$ or FeCB solution (Table 1). In both cases, the medium was allowed to stand for $30 \mathrm{~min}$ at room temperature after mixing it with the $\mathrm{CB}$ or FeCB solution.

Analysis of chicken $T f$ subspecies. Chicken $T f$ subspecies in culture medium were analyzed by PAGIF, DIF and staining (17). The culture medium was centrifuged for $5 \mathrm{~min}$ in an Eppendorf centrifuge to remove insoluble materials, after which the supernatant formed was analyzed directly on PAGIF gel. The subspecies were, when necessary, treated as described above in order to iron-load the Tfs therein. The respective concentrations of the remaining holoTf and the total $\mathrm{Tf}$ in the culture medium were determined without and after iron-loading by PAGIF, DIF, staining and densitometry as described previously (17). Under our analytical conditions, the apotypes of oTf and monoferric Tfs were not focused as a distinct band.

Iodination of Tf. Chicken holoTf was iodinated by the chloramine-T method as described previously $(7,10)$, the specific activity being $4.3 \times 10^{9} \mathrm{cpm} / \mathrm{nmole}$ Tf. Chicken-iodinated Tf had nearly the same growth-supporting activity with myogenic chicken cells as that of 
unlabeled Tf.

Assay of internalized ${ }^{125}$ I-Tf. Myogenic chicken cells were cultured in $85 \%$ Eagle's MEM and $15 \%$ horse serum at $37^{\circ} \mathrm{C}$ for $12 \mathrm{~h}$. The inoculated dishes were washed twice with washing solution (Eagle's MEM containing $10 \mathrm{mM}$ HEPES, pH 7.5) then incubated in medium containing $85 \%$ Eagle's MEM and $15 \%$ horse serum in a $\mathrm{CO}_{2}$ incubator at $37^{\circ} \mathrm{C}$ for $1 \mathrm{~h}$. After again being washed twice with the same solution, the cells were incubated at $\mathrm{pH} 7.5$ in a total volume of $0.5 \mathrm{ml}$ of a buffer solution composed of Hanks' balanced solution, $5 \mathrm{mg} / \mathrm{ml}$ bovine serum albumin, $10 \mathrm{mM}$ HEPES and $0.06 \mathrm{mg} / \mathrm{ml}$ Kanamycin plus $1.1 \times$ $10^{-3}$ nmoles of 125 I-holoTf.

At various times during incubation the radioactive medium was removed, and each dish was washed with ice-cold buffer solution then with $0.2 \mathrm{M}$ acetic acid- $0.5 \mathrm{M} \mathrm{NaCl}$ to distinguish the internalized Tf from the cell surface-bound Tf $(10,12)$. Nonspecific binding of 125I-Tf was determined from an assay containing a 2,000-fold excess of unlabeled Tf, the net radioactivity of the internalized $\mathrm{Tf}$ being obtained by subtracting the nonspecific binding from the total radioactivity. The cells were made soluble in $1.2 \mathrm{ml}$ of $2 \mathrm{~N} \mathrm{NaOH}$, after which the radioactivity was measured in a gamma counter (Model 5230, Packard, U.S.A.).

Preparation of gamma globulin. Anti-Tf gamma globulin (IgG) was obtained from immunized rabbit serum by ammonium sulfate precipitation and DEAE-cellulose column chromatography as described previously (15).

SDS polyacrylamide-gel electrophoresis of immunoprecipitates. Immunoprecipitation was carried out by adding sufficient IgG to the culture media to completely precipitate antigens (16.2 $\mu \mathrm{g}$ anti-oTf IgG/ $\mu \mathrm{g}$ of oTf). The precipitates were washed repeatedly with $0.15 \mathrm{M}$ $\mathrm{NaCl}$ then analyzed by SDS slab polyacrylamide-gel electrophoresis according to Laemmli (20), as described elsewhere (15).

Other determinations. Protein concentration was assayed by the method of Lowry et al. (21) using bovine serum albumin as the standard. The total iron-binding and unsaturated iron-binding capacities of the horse serum were determined as described elsewhere (16).

\section{RESULTS}

Internalization of chicken holoTf in myogenic chicken cells was ascertained by determining the ${ }^{125} \mathrm{I}-\mathrm{Tf}$ not released from the cells by acid treatment $(10,12)$. Chicken holoTf was internalized temperature dependently as in other cells $(4,10)$ (Fig. 1).

Because chicken Tf subspecies, which differ in their carbohydrate chain structures, have distinct isoelectric points, each holotype was focused as a distinct band on the PAGIF gel. The isoelectric point of the holotype is 6.1 for oTf, 5.9 for Tf1 and 5.7 for Tf2, and is dependent on the number of terminal sialic acid residues in the carbohydrate chain (15). Therefore, if Tf subspecies undergo molecular changes in their protein or carbohydrate moieties, the changes should be detectable on the PAGIF gel. We thus examined whether the PAGIF patterns of Tf species changed before and after recycling.

Myogenic cells were plated at an initial density of $5 \times 10^{5}$ cells per $35-\mathrm{mm}$ dish, each dish containing $2.5 \mathrm{ml}$ of culture medium ( $85 \%$ Eagle's MEM- $15 \%$ horse serum) with or without the chicken holoTf subspecies $(5 \mu \mathrm{g} / \mathrm{ml})$. Under these conditions, each holoTf subspecies equally supported myogenic cell growth (Fig. 2) and the accumulation of CK activity (Fig. 3). Changes in the PAGIF patterns of chicken Tf subspecies in the culture medium are shown in Fig. 4. As judged from the staining, the gradual disappearance of holoTf and the appearance of apoTf were concomitant 


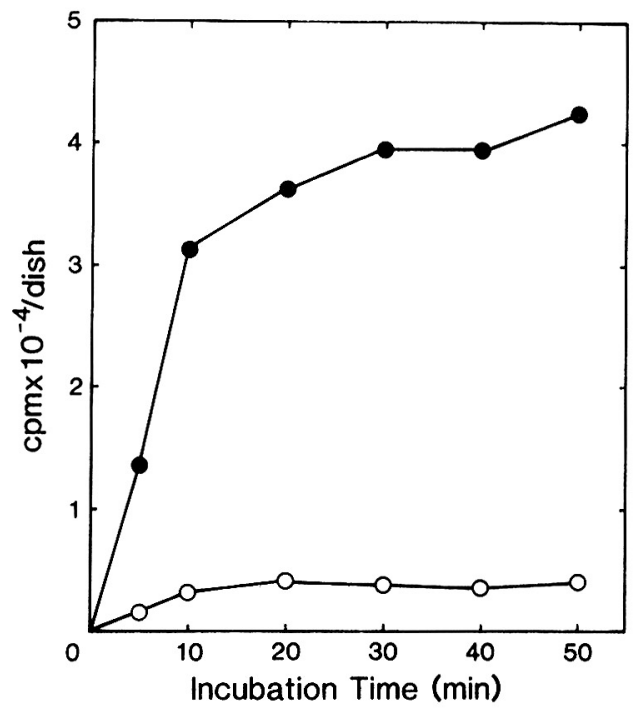

Fig. 1. Internalization of chicken Tf in myogenic chicken cells. Cells $\left(9.05 \times 10^{5}\right.$ per $35-\mathrm{mm}$ dish) were incubated with $2.2 \mathrm{nM}$ chicken ${ }^{125} \mathrm{I}-\mathrm{Tf}$ at $4^{\circ} \mathrm{C}$ or $37^{\circ} \mathrm{C}$. Radioactivity of the internalized Tf was determined as described in the text. $\bigcirc, 4^{\circ} \mathrm{C} ; \bullet, 37^{\circ} \mathrm{C}$.
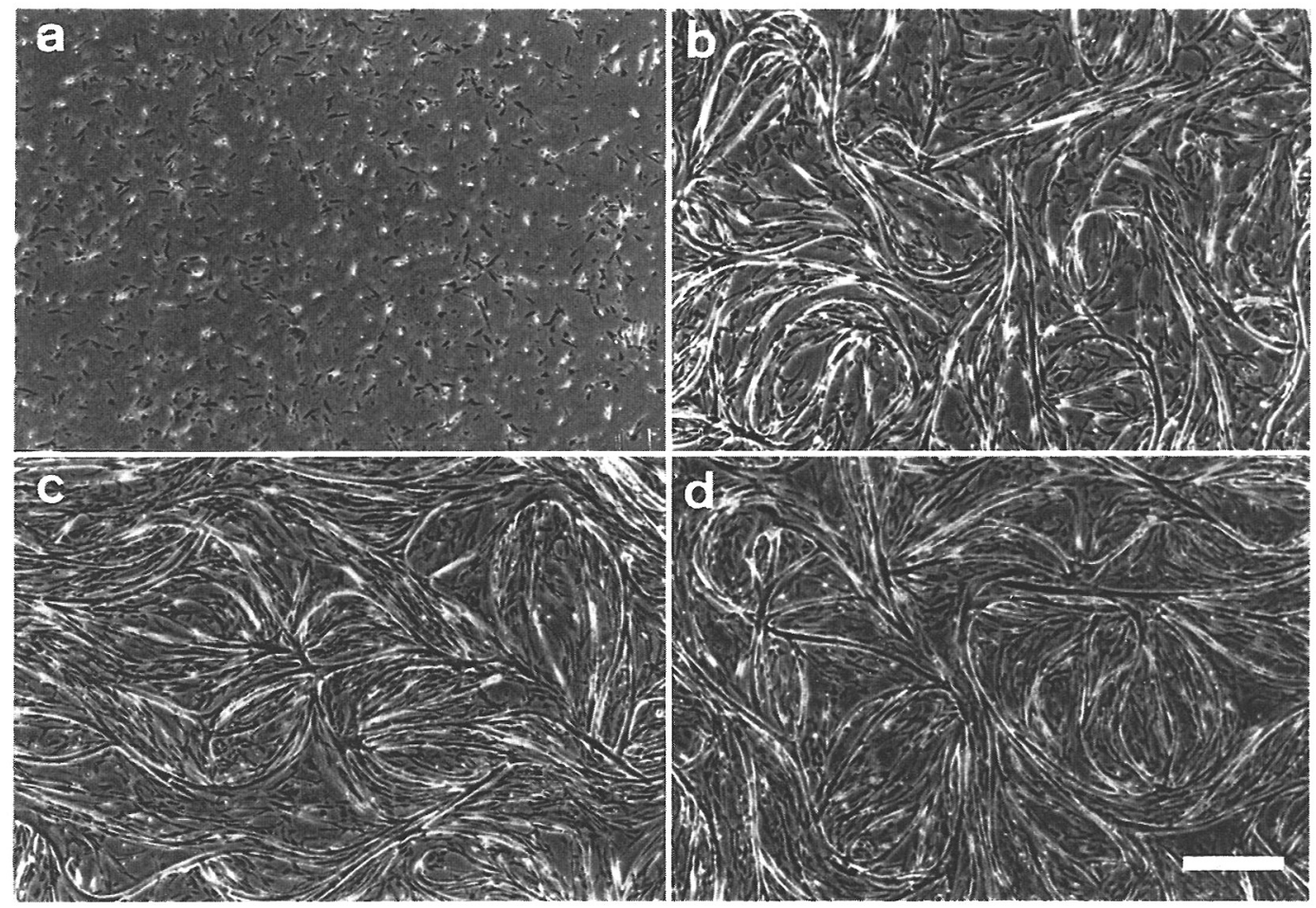

Fig. 2. Cultures showing the growth-supporting activity of Tfs. Myogenic chicken cells were cultured for 4 days with a supplement of (a) nothing, (b) oTf, (c) Tf1 or (d) Tf2. Chicken Tfs were added at $5 \mu \mathrm{g} / \mathrm{ml}$. For details of the experimental conditions used, see the text. The bar represents $0.5 \mathrm{~mm}$. 


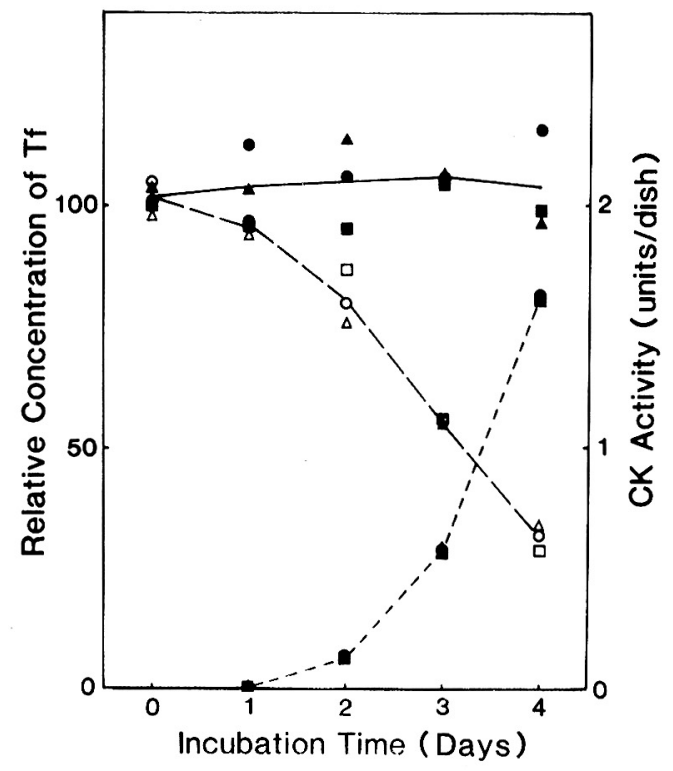

Fig. 3. Myogenic cell growth and changes in the concentrations of the remaining holoTf and total Tf in the culture medium. -..., CK activity; ---, concentration of the remaining holoTf; - concentration of total Tf; $\bigcirc \bullet$, oTf; $\triangle \Delta$, Tf $1 ; \square \mathbf{a}$, Tf 2 . In the remaining holoTf and total Tf assays, the amounts of holoTfs were determined densitometrically from stained gels (Fig. 4 without and Fig. 6 after iron-treatment). Points represent the means of three separate dishes. For details of other experimental procedures, see the text.

Fig. 4. PAGIF patterns of chicken $\mathrm{Tf}$ subspecies in culture media. After the media from the cultures shown in Figs. 2 and 3 had been centrifuged to remove insoluble materials, $5 \mu \mathrm{l}$ portions of their supernatants were analyzed directly on a PAGIF gel. Tfs were visualized by DIF and Coomassie Blue staining.

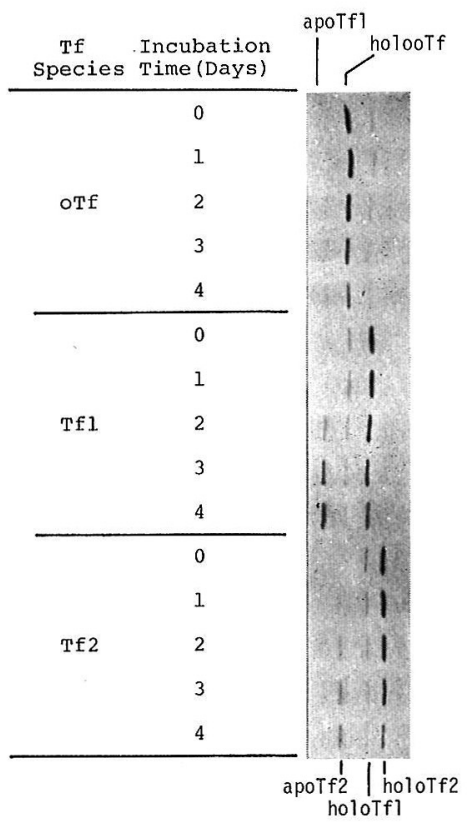


with cell growth. No bands other than the holo- and apoTf were present, and no degradation product was detected. In this medium system, no marked loss of iron from chicken holoTf took place in the absence of cells (data not shown). PAGIF gels, such as the representative ones shown in Fig. 4, were scanned densitometrically and the concentration of the remaining holoTf determined. The results summarized in Fig. 3 again indicate the gradual disappearance of holoTf.

Following an addition of FeCB solution to the "used" culture medium to iron-load all the Tfs, PAGIF analyses of the Tf subspecies were made which demonstrated that all the Tfs in the culture medium were focused at positions identical to those of standard "new" holoTfs (data not shown, but see Fig. 6). The concentration of Tfs focused in this way was determined densitometrically (Fig. 3). Our results indicate that there were no major changes in the concentration of the total Tfs in the culture medium during incubation. In combination, these qualitative and quantitative data strongly suggest that recycled Tfs preserve their molecular intactness; our Tfs did not undergo intracellular modification or degradation in the culture system used.

Under our culture conditions, chicken holoTfs provided growth-supporting activity for chicken cells, but apoTfs did not $(11,14-16)$. Therefore, even if a given $\mathrm{Tf}$ recycles

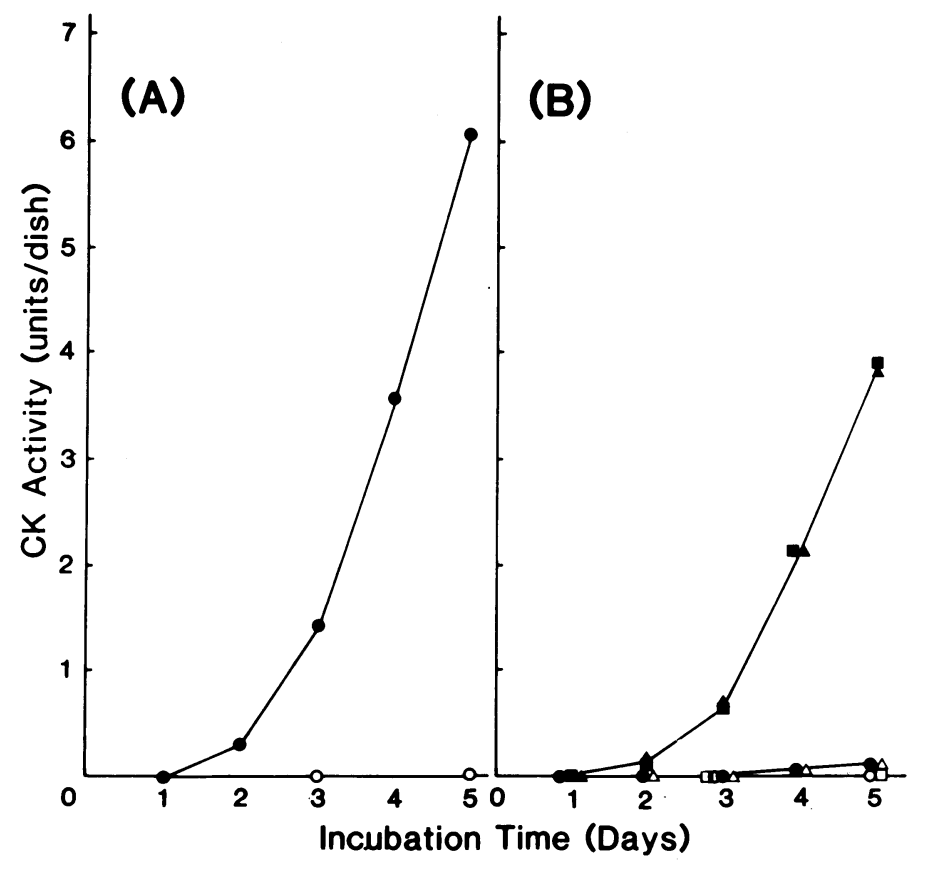

Fig. 5. Restoration of the myotrophic activity of recycled $\mathrm{Tf}$ by iron-reloading. (A) 1st culture. Myogenic chicken cells were cultured at an initial cell density of $5 \times 10^{5}$ per $35-\mathrm{mm}$ dish in $1.5 \mathrm{ml}$ of fresh culture medium FCM [15] (85\% Eagle's MEM-15\% horse serum) or FCM [15, Tf] (FCM [15] plus $10 \mu \mathrm{g} / \mathrm{ml} \mathrm{Tf} 2) . \bigcirc, \mathrm{FCM}[15]$; ๑, FCM [15,Tf]. (B) 2nd culture. Each culture dish contained $2.3 \mathrm{ml}$ of medium and $0.2 \mathrm{ml}$ of cell suspension $\left(1.25 \times 10^{6} \mathrm{cells} / \mathrm{ml}\right.$ of FCM [30]). $\bigcirc$, medium A; ๑, medium B; $\Delta$, medium C; $\mathbf{\square}$, medium D; $\triangle$, medium $\mathrm{E}$ and $\square$, medium F. For abbreviations and media compositions, see Table 1. Points represent the means of two dishes. For experimental details see the text. 
intact as an apoform in the culture medium, it no longer has growth-supporting activity. But, if it is intact, it should regain its bioactivity on being reloaded with iron. For this reason, we examined the Tf in a myogenic chicken cell system.

This experiment was based on the following facts: (1) In the absence of chicken Tf or the presence of apoTf, culture medium composed of Eagle's MEM and horse serum provided no growth-supporting activity with chicken cells. But, when supplemented with iron-loaded chicken Tfs, the medium acquired the ability to support cell growth $(11,14,15)$. This is ascribed to the specificity of this $\mathrm{Tf}$ for cell growth; horse $\mathrm{Tf}$ at a relatively high concentration in the culture medium had no effect on chicken cells (22). (2) The iron-saturation of the Tfs in horse serum is low. In the horse serum we used, the respective total iron-binding and unsaturated iron-binding capacities were $80.6 \mu \mathrm{M}$ and $46.3 \mu \mathrm{M}$; that is, the saturation level was $43 \%$. (3) Although free iron supports the growth of myogenic chicken cells when at a relatively high concentration $(9,23)$, when added as a supplement to culture medium containing horse serum it is scavenged by the unsaturated horse Tf within the limit of the unsaturated iron-binding capacity.

Myogenic chicken cells were cultured at an initial density of $5 \times 10^{5}$ cells per $35-\mathrm{mm}$ dish for 5 days in $1.5 \mathrm{ml}$ of fresh culture medium (FCM) composed of $85 \%$ Eagle's MEM- $15 \%$ horse serum with $(10 \mu \mathrm{g} / \mathrm{ml})$ or without chicken Tf 2 (1st culture). Whereas the cells did not grow in the absence of chicken $\mathrm{Tf}$, they grew well in its presence forming myotubes and building up $\mathrm{CK}$ activity (Fig. 5A). At the same time, the

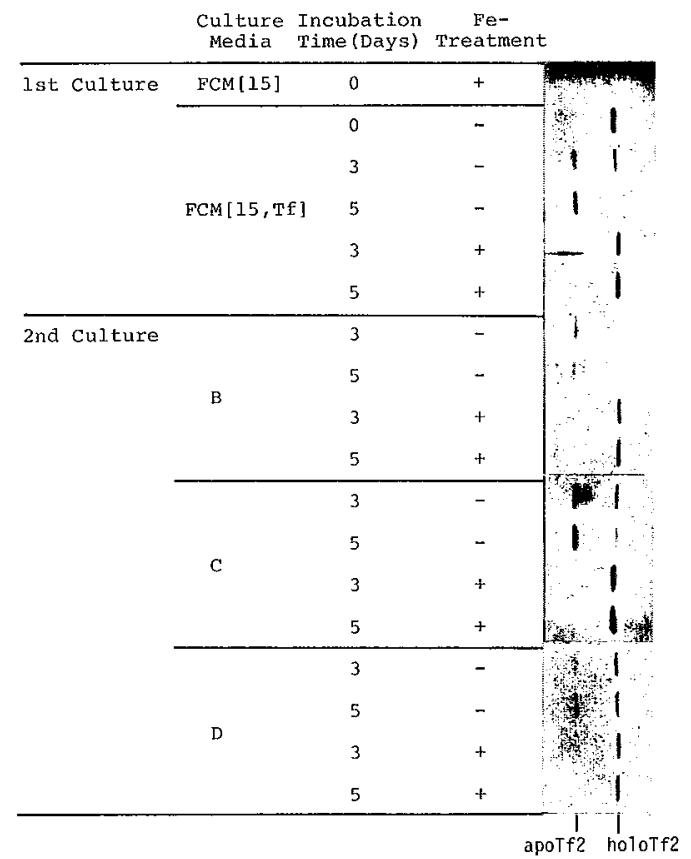

Fig. 6. PAGIF patterns of $\mathrm{Tfs}$ in the 1 st and 2 nd culture media. The media used were from the cultures described in Fig. 5. After insoluble material had been removed by centrifugation, $5 \mu 1$ of each supernatant was analyzed on a PAGIF gel without and after, iron-treatment. Chicken Tfs were visualized selectively by DIF and staining. 
TABLE 1. COMPOSITIONS OF MEDIA FOR THE 2ND CULTURE

\begin{tabular}{|c|c|c|c|c|c|}
\hline UCM [15] & $\mathrm{UCM}[15, \mathrm{Tf}]$ & $\mathrm{UCM}[15, \mathrm{Tf}]$ & $\mathrm{UCM}[15, \mathrm{Tf}]$ & FCM [30] & $\mathrm{UCM}[15, \mathrm{Tf}]$ \\
\hline$+\mathrm{CB}$ & $+\mathrm{CB}$ & $+\mathrm{CB}$ & $+\mathrm{FeCB}$ & $+\mathrm{FeCB}$ & $+\mathrm{FeCB}$ \\
\hline$\downarrow+$ FCM [30] & + FCM [30] & $+\mathrm{FCM}[30]$ & + FCM [30] & $\downarrow+\underset{[15, \mathrm{Tf}]}{+\mathrm{UCM}}$ & $\downarrow+$ FCM [30] \\
\hline$\downarrow+$ saline & + saline & $+\mathrm{Tf}$ & + saline & $\downarrow+$ saline & $\downarrow+\operatorname{IgG}$ \\
\hline Medium A & Medium B & Medium C & Medium D & Medium E & Medium $\mathrm{F}$ \\
\hline
\end{tabular}

UCM [15], 5-day-used 1st culture medium containing 15\% horse serum and no chicken Tf; UCM [15, Tf], 5-day-used 1st culture medium containing $15 \%$ horse serum and chicken $\mathrm{Tf}(10 \mu \mathrm{g} / \mathrm{ml}) ; \mathrm{CB}$, citrate-bicarbonate solution (1/1000); $\mathrm{FeCB}, \mathrm{FeCl}_{3}$-citrate-bicarbonate solution $(1 / 1000)$; $\mathrm{FCM}$ [30], fresh culture medium containing $30 \%$ horse serum (1); saline, $0.15 \mathrm{M} \mathrm{NaCl}(1 / 100)$; Tf, chicken $\mathrm{Tf}$ solution ( $1 \mathrm{mg} / \mathrm{ml}$ of saline) (1/100); IgG, anti-chicken Tf 2 IgG solution $(9.4 \mathrm{mg} / \mathrm{ml}$ of saline) $(1 / 100)$. The number $1,1 / 100$ or $1 / 1000$ in parentheses indicates the volume of each solution relative to that of UCM.

holoTfs in the culture medium disappeared, as described above (Fig. 6). On the PAGIF gel, almost no holoTf was detected in the 5-day culture medium. On day 5, the "used" culture medium (UCM) was collected and centrifuged to remove insoluble material. Using this UCM and FCM, six kinds of culture media were prepared for 2nd culture (Table 1). Medium A contained no chicken Tf, medium B contained "used" (recycled) Tf, medium C contained "used" Tf and newly supplemented Tf, medium D contained "used"' Tf reloaded with iron, and media E and F were controls used to assess the absence of the growth-supporting free iron in medium D. Antichicken Tf IgG completely inhibited the myotrophic activity of chicken Tf when introduced into the culture medium $(11,15)$. The concentrations of "used" Tf in media B-E and that of the newly supplemented Tf in medium C were equal $(5 \mu \mathrm{g} / \mathrm{ml})$. The second culture with freshly prepared myogenic cells was done in $2.5 \mathrm{ml}$ of medium at an initial density of $2.5 \times 10^{5}$ cells per $35-\mathrm{mm}$ dish (Fig. 5B).

In medium $\mathrm{F}$, as in $\mathrm{A}$, cells did not grow; instead they degenerated. This means that there was no free iron present in medium $\mathrm{D}$ above the threshold concentration, or perhaps none was present, presumably having been scavenged by the horse Tf. In media $\mathrm{E}$ and $\mathrm{B}$, only slight growth was found. This suggests that a very small amount of iron-loaded Tf survived the 1st culture. Medium D supported cell growth, the amount of growth being almost equal to that obtained with medium $\mathrm{C}$. This shows that the concentrations of bioactive chicken Tfs in media $\mathrm{C}$ and D were comparable, as was ture of those of oTf and Tf1 (data not shown).

\section{DISCUSSION}

We have found additional evidence for the molecular intactness of recycled Tf. First we showed that when reloaded with iron, recycled $\mathrm{Tf}$ is indistinguishable from standard Tf on a PAGIF gel. This indicates that during its intracellular and extracellular movement $\mathrm{Tf}$ does not undergo molecular changes to its carbohydrate chain (such as desialylation, sialylation or endoglycosylic cleavage) because such changes would have been reflected directly in its behavior on the PAGIF gel. It also is probable that no change occurred in its protein moiety. Recycled Tf immunoprecipitated by anti-Tf IgG had an electrophoretic mobility indistinguishable from that of standard 


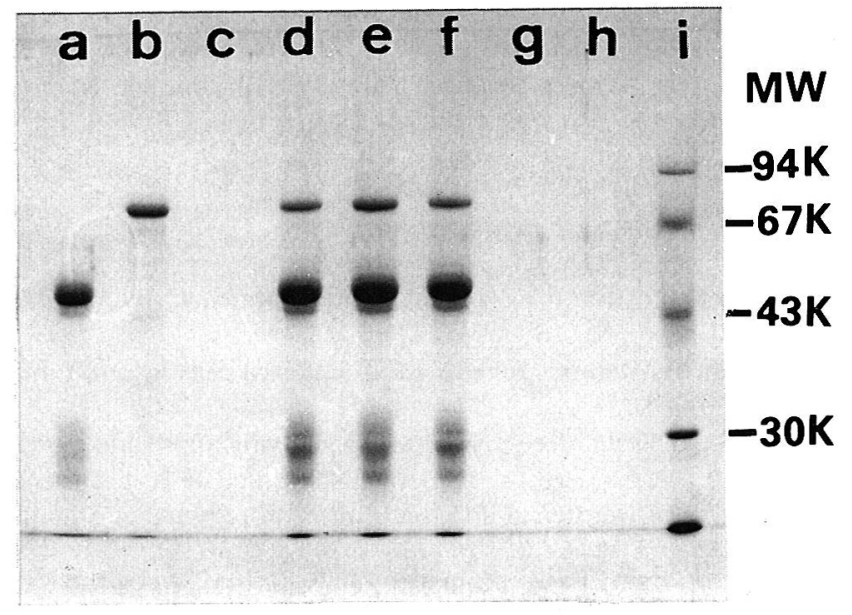

Fig. 7. SDS polyacrylamide-gel electrophoresis of the immunoprecipitates of chicken oTf in culture media. Myogenic chicken cells were cultured at an initial density of $5 \times 10^{5}$ per $35-\mathrm{mm}$ dish in $1.5 \mathrm{ml}$ of culture medium ( $85 \%$ Eagle's MEM-15\% horse serum with, or without, oTf $(10 \mu \mathrm{g} / \mathrm{ml})$ ). Under these conditions, very little holoTf was detected in the 5-day culture medium (Fig. 5). Samples were electrophoresed on a $10 \%$ polyacrylamide-gel. Protein bands that formed were stained with Coomassie Brilliant Blue R-250. (a) anti-oTf IgG; (b) oTf; (c) precipitate (ppt) of anti-oTf IgG+ 5-day medium that contained neither oTf nor cells; (d) ppt of anti-oTf IgG+0-day medium that contained either oTf or cells; (e) ppt of anti-oTf IgG+5-day medium that contained either oTf or cells; (f) ppt of anti-oTf IgG +5-day medium that contained oTf but not cells; (g) ppt of the preimmune control $\mathrm{IgG}+0$-day medium that contained either oTf or cells; (h) ppt of the preimmune control IgG +5-day medium that contained either oTf or cells and (i) standard markers (rabbit muscle phosphorylase b, $94 \mathrm{~K}$; bovine serum albumin, $67 \mathrm{~K}$; egg white ovalbumin, $43 \mathrm{~K}$; bovine erythrocyte carbonic anhydrase, $30 \mathrm{~K}$ ). For details of other experimental procedures, see the text.

Tf on an SDS-polyacrylamide gel (Fig. 7), as documented by Klausner et al. (19).

No degradation products with molecular weights lower than the standard Tf were found. Possibly the cells synthesize and excrete Tf, which compensates for the Tf concentration in the culture medium; but, this is unlikely, because no chicken Tf was detected in the culture medium when cells were grown in the presence of free iron (in place of Tf) as the growth-supporting substance (data not shown). Our results suggest not only that the Tfs recycled in the culture medium have intact molecular forms but that almost all of the internalized $\mathrm{Tf}$ are externalized intact.

We also showed that recycled Tf regained its growth-supporting ability when reloaded with iron. The retention of growth-supporting ability does not necessarily indicate molecular intactness because $\mathrm{Tf}$ monoferric half-molecule fragments are capable of delivering their iron to cells $(6,13)$, although they are markedly less efficient in this delivery. Our unpublished data also show that the monoferric halfmolecules of chicken $\mathrm{Tf}$ have positive growth-supporting activity for chicken cells, but are markedly less efficient for growth than the intact molecules. Thus, the combined results of our experiments, in which electrophoretic behavior and growthsupporting activity were shown to be indistinguishable in iron-reloaded "used" Tf and standard "new" Tf, are strong evidence for the molecular intactness of recycled Tf. 
Acknowledgements. This research was supported by a grant (NCNMMD, \$8301) from the National Center for Nervous, Mental and Muscular Disorders of the Ministry of Health and Welfare and a Grant-in-Aid for Special Project Research ( $\$ 58119008)$ from the Ministry of Education, Science and Culture of Japan.

\section{REFERENCES}

1. Aisen, P. and I. Listowski. Iron transport and storage proteins. Ann. Rev. Biochem. 49, 357393, 1980

2. Barnes, D. and G. Sato. Methods for growth of cultured cells in serum-free medium. Anal. Biochem. 102, 255-270, 1980

3. Barnes, D. and G. SAto. Serum-free cell culture: a unifying approach. Cell 22, 649-655, 1980

4. Ciechanover, A., A.L. Schwartz, A. Dautry-Versat and H.F. Lodish. Kinetics of internalization and recycling of transferrin and the transferrin receptor in a human hepatoma cell line. J. Biol. Chem. 258, 9681-9689, 1983

5. Dautry-Versat, A., A. Ciechanover and H.F. Lodish. pH and the recycling of transferrin during receptor-mediated endocytosis. Proc. Natl. Acad. Sci. U.S.A. 80, 2258-2262, 1983

6. EsPARZA, I. and J.H. BROCK. The interaction of bovine transferrin and monoferric transferrin fragments with rabbit retioulocytes. Biochim. Biophys. Acta 624, 4769-489, 1980

7. Greenwood, F.C., W.M. HunTer and J.S. Glover. The preparation of ${ }^{131}$ I-labelled human growth hormone of high specific radioactivity. Biochem. J. 89, 114-123, 1963

8. Harding, C. and P. Stahl. Transferrin recycling in reticulocytes: $\mathrm{pH}$ and iron are important determinants of ligand binding and processing. Biochem. Biophys. Res. Comm. 113, 650-658, 1983

9. Hasegawa, T., K. Saito, I. Kimura and E. Ozawa. $\mathrm{Fe}^{3+}$ promotes in vitro growth of myoblasts and other cells from chick embryos. Proc. Jap. Acad. 57(B), 206-210, 1981

10. Hasegawa, T. and E. Ozawa. Transferrin receptor on chick fibroblast cell surface and the binding activity in relevance to the growth promoting activity of transferrin. Develop. Growth Differen. 24, 581-587, 1982

11. II, I., I. Kimura and E. OzaWA. A myotrophic protein from chick embryo extract: Its purification, identity to transferrin, and indispensability for avian myogenesis. Dev. Biol. 94, 366-377, 1982

12. KARIN, M. and B. MINZ. Receptor-mediated endocytosis of transferrin in developmentally totipotent mouse teratocarcinoma stem cells. J. Biol. Chem. 256, 3245-3252, 1981

13. Keung, W.-W. and P. Azari. Structure and function of ovotransferrin. II. Iron-transferring activity of iron-binding fragments of ovotransferrin with chicken embryo red cells. J. Biol. Chem. 257, 1184-1188, 1982

14. Kimura, I., T. Hasegawa, T. Miura and E. Ozawa. Muscle trophic factor is identical to transferrin. Proc. Jap. Acad. 57(B), 200-205, 1981

15. Kimura, I., T. Hasegawa and E. Ozawa. Indispensability of iron-bound chick transferrin for chick myogenesis in vitro. Develop. Growth Differen. 24, 369-380, 1982

16. Kimura, I. and E. Ozawa. Further studies on the developmental change in myotrophic activity of chicken serum: Relation between activity and transferrin. Develop. Growth Differen. 25, 523-529, 1983

17. Kimura, I. Developmental change in microheterogeneity of serum transferrin of chicken. Develop. Growth Differen. 25, 531-535, 1983

18. Klausner, R.D., G. Ashwell, J. Van Renswoude, J.B. Harford and K.R. Bridges. Binding of apotransferrin to K562 cells: Explanation of the transferrin cycle. Proc. Natl. Acad. Sci. U.S.A. 80, 2263-2266, 1983

19. Klausner, R.D., J. Van Renswoude, G. Ashwell, C. Kempf, A.N. Schechter, A. Dean and K.R. BRIDGES. Receptor-mediated endocytosis of transferrin in K562 cells. J. Biol. Chem. 258, 4715-4724, 1983

20. LAEMMLI, U.K. Cleavage of structural proteins during the assembly of the head of bacteriophage 
T4. Nature 227, 680-685, 1970

21. Lowry, O.H., N.J. Rosebrough, A.L. Farr and R.J. Randall. Protein measurement with Folin phenol reagent. J. Biol. Chem. 193, 265-275, 1951

22. Ozawa, E. and Y. Hagiwara. Avian and mammalian transferrins are required for chick and rat myogenic cell growth in vitro, respectively. Proc. Jap. Acad. 57(B), 406-409, 1981

23. Saito, K., Y. Hagiwara, T. Hasegawa and E. Ozawa. Indispensability of iron for the growth of cultured chick cells. Develop. Growth Differen. 24, 571-580, 1982

24. Willingham, H.C., J.A. Hanover, R.B. Dickson and I. Pastan. Morphologic characterization of the pathway of transferrin endocytosis and recycling in human KB cells. Proc. Natl. Acad. Sci. U.S.A. 81, 175-179, 1984

(Received for publication, December 28, 1984) 